\title{
Apligraf as an Alternative to Skin Grafting in the Pediatric Population
}

\author{
Morgan Eudy ${ }^{1}$, Christi L. Eudy ${ }^{1}$, Samuel Roy ${ }^{2}$ \\ 1. Surgery, Campbell University School of Osteopathic Medicine, Salisbury, USA 2. Plastic and Reconstructive Surgery, \\ Piedmont Plastic and Oral Surgery, Salisbury, USA
}

Corresponding author: Morgan Eudy, m_eudy0223@email.campbell.edu

\begin{abstract}
Split-thickness skin grafting and healing by secondary intention are the most common options for the treatment of full-thickness skin injuries. This case explores Apligraf (Organogenesis Inc., Canton, Massachusetts) as an alternative treatment for full-thickness skin injuries in the pediatric population. Apligraf, a bioengineered living cell construct, is an advanced wound care modality that is commonly used to treat chronic, nonhealing venous leg ulcers and diabetic foot ulcers. This case demonstrates Apligraf as a viable, if not superior, treatment option for full-thickness skin injury.
\end{abstract}

Categories: Pediatrics, Pediatric Surgery, Plastic Surgery

Keywords: bioengineered living cell constructs, apligraf, split thickness skin graft, skin graft, full thickness wounds, full thickness skin graft, pediatric plastic surgery

\section{Introduction}

Bioengineered living cell constructs (BLCC), such as Apligraf (Organogenesis Inc., Canton, Massachusetts), are approved by the Food and Drug Administration (FDA) for the treatment of chronic, nonhealing venous leg ulcers (VLU) and diabetic foot ulcers (DFU) [1]. Apligraf is a living, bi-layered skin substitute formed by human neonatal foreskin-derived keratinocytes and fibroblasts in a bovine type 1 collagen lattice [1]. Studies looking into the mechanism of action of BLCC have demonstrated that they are able to phenotypically convert chronic nonhealing wounds to a more acute inflammatory environment that can promote healing [1]. This is achieved by inducing genes that are responsible for acute inflammation healing, stimulating wound edge keratinocytes, and attenuating Wnt/ $\beta$-catenin [1].

Review began 05/22/2021 Review ended 06/27/2021 Published 07/07/2021

\section{() Copyright 2021}

Eudy et al. This is an open access article distributed under the terms of the Creative Commons Attribution License CC-BY 4.0., which permits unrestricted use, distribution, and reproduction in any medium, provided the original author and source are credited.

\section{Case Presentation}

Our patient, a three-year-old female, presented after a fall on a treadmill, resulting in a $5 \mathrm{~cm} \times 4 \mathrm{~cm}$ fullthickness skin injury on the right, distal 1/3rd of the leg (Figure 1). She was initially treated with silver sulfadiazine, and a split-thickness skin graft (STSG) was planned for definitive treatment. The patient's family consulted a plastic surgeon searching for additional treatment options, with specific concerns about cosmetics and creating a donor site scar. 


\section{Cureus}

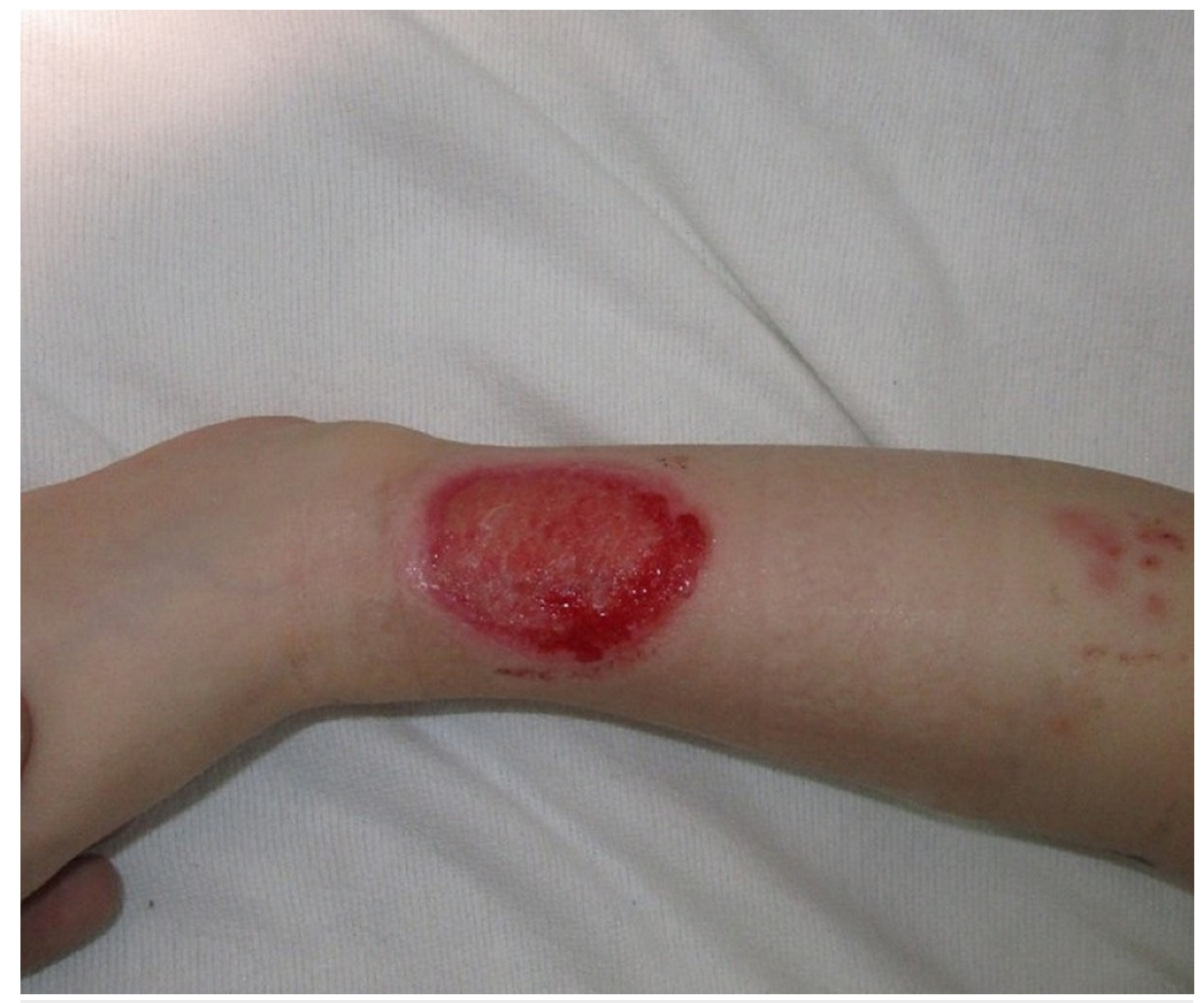

\section{FIGURE 1: Initial consultation at the plastic surgeon's office}

At this point, the options for treatment included STSG, healing by secondary intention, and advanced modalities such as Apligraf. After discussing the options with the patient's family, they elected Apligraf.

To place Apligraf, the patient was taken to the operating room and under general anesthesia, the wound was first debrided sharply and irrigated using pulsa-vac and then the wound bed was cauterized for hemostasis. Apligraf was fenestrated make the membrane more permeable, applied to the wound, and secured using multiple resorbable sutures as shown in Figure 2. A wound vacuum-assisted closure (VAC) dressing was placed for five days. 


\section{Cureus}

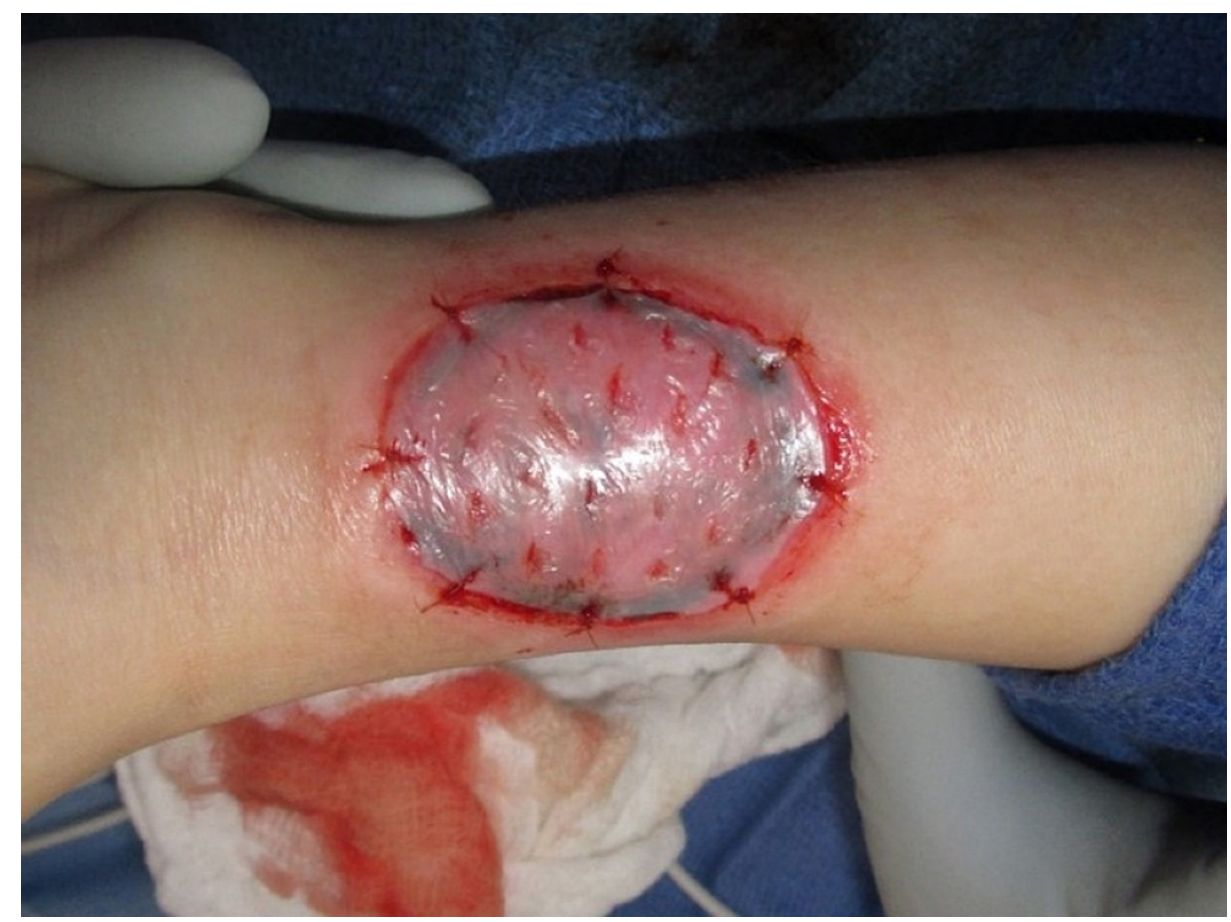

FIGURE 2: Immediately after the procedure, with the initial Apligraf in place

Apligraf was reapplied in the office on postoperative days 12 and 24 and held in place with Steri-Strips, Adaptic (vaseline gauze), $4 \times 4$ gauze, Kerlix, and Coban. Figure 3 shows postoperative day 39, after the application of the three total Apligrafs. Figure 4 shows the complete resolution of the full thickness injury 11 months after the initial placement of the Apligraf. 


\section{Cureus}

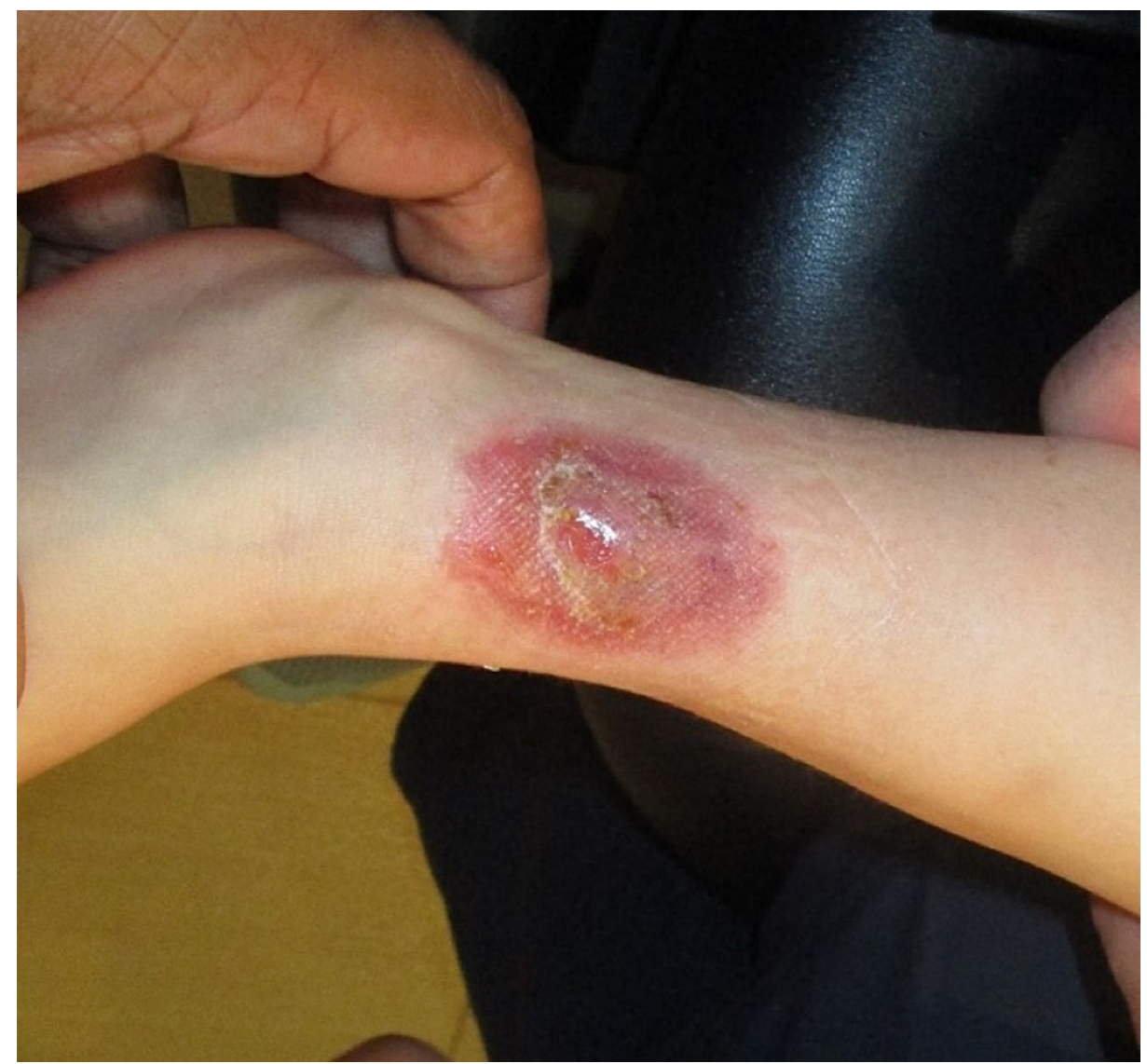

FIGURE 3: Postoperative day 39, after the application of three Apligrafs 


\section{Cureus}

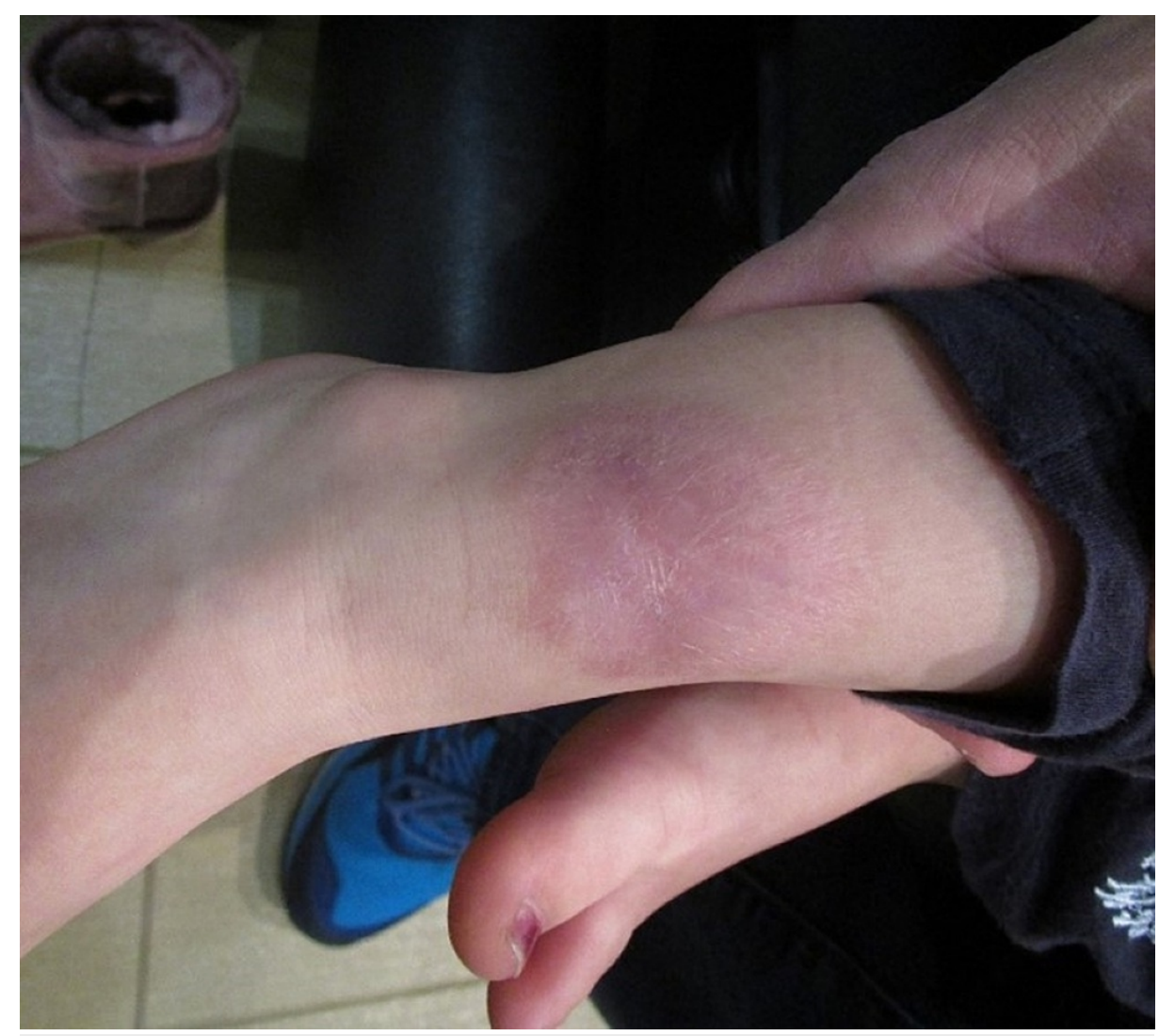

FIGURE 4: Eleven months postoperation

\section{Discussion}

This case demonstrates Apligraf as a valid alternative to STSG in full thickness skin injuries. While a STSG is typically the treatment of choice for wounds such as in this case, there are a few draw backs. Autografts require the creation of a donor site, adding an additional scar and recovery time. The other treatment option that was proposed to the family was healing by secondary intention. The downside to this approach was the possible development of a severe wound contracture and the functional implications this could have to the patient later in life. The cosmetic appearance associated with the creation of a donor site or healing via secondary intention were a major concern for the patient's family and the reason they opted for an alternative modality.

While Apligraf is FDA approved for VLU and DFU, it has been used in several other clinical scenarios. One study used Apligraf in surgical wound defects after skin cancer removals as an alternative to skin grafting or healing by secondary intention [2]. While the participation of the study was low (17 adults) and there was no control group, the authors of the study concluded that they were pleased with the cosmetic results of using Apligraf [2]. The authors felt there was improved healing when using the Apligraf versus healing by secondary intention [2].

In the pediatric population, Apligraf has been used in the treatment of epidermolysis bullosa. One study of 9 pediatric patients found the use of Apligraf resulted in rapid healing, easier wound care, improved ambulation and dexterity versus skin grafting [3].

Despite the positive results surrounding the use of Apligraf, there are very limited studies and cases of its use in the pediatric population. Additional studies need to be conducted to fully compare the use of Apligraf versus STSG and healing by secondary intention in pediatric patients. An additional consideration for providers and patients considering Apligraf is cost. According to the 2021 Medicare rates from Organogenesis website, Apligraf costs anywhere from approximately $\$ 870-\$ 3,500$ depending on multiple factors. Apligraf is not currently covered by insurance outside of its FDA approved indications of VLU and DFU.

\section{Conclusions}

This case brings to light the pros and cons of the standard treatment of full thickness skin injuries, with an emphasis on cosmetic concerns. Apligraf is a viable option for treatment of burns and produces pleasing 


\section{Cureus}

cosmetic results in the pediatric population.

\section{Additional Information}

\section{Disclosures}

Human subjects: Consent was obtained or waived by all participants in this study. Conflicts of interest: In compliance with the ICMJE uniform disclosure form, all authors declare the following: Payment/services info: All authors have declared that no financial support was received from any organization for the submitted work. Financial relationships: All authors have declared that they have no financial relationships at present or within the previous three years with any organizations that might have an interest in the submitted work. Other relationships: All authors have declared that there are no other relationships or activities that could appear to have influenced the submitted work.

\section{References}

1. Stone RC, Stojadinovic O, Rosa AM, et al.: A bioengineered living cell construct activates an acute wound healing response in venous leg ulcers. Sci Transl Med. 2017, 9:8611. 10.1126

2. Eaglstein WH: A composite skin substitute (graftskin) for surgical wounds. A clinical experience . Dermatologic surgery. 1995, 21:839-843. 10.1111/j.1524-4725.1995.tb00709.x

3. Fivenson DP, Scherschun L, Choucair M, Kukuruga D, Young J, Shwayder T: Graftskin therapy in epidermolysis bullosa. J Am Acad Dermatol. 2003, 48:886-92. 10.1067/mjd.2003.502 